\title{
Application of MOOSY32 eNose to Assess the Effects of Some Post Harvest Treatments on the Quality of 'Salustiana' Orange Juice
}

\author{
Cupane $\mathbf{M}^{1,2}$, Pelegri-Sebastia $\mathrm{J}^{3 *}$, Climent $\mathrm{E}^{3}$, Guarrasi $\mathrm{V}^{2}$, Sogorb $\mathrm{T}^{3}$ and Germana $\mathrm{MA}^{1}$
}

${ }^{1}$ Department of Agricultural and Forestry Science (SAF), Università degli Studi di Palermo, Viale delle Scienze 11, Ed. 4, 90128, Palermo, Italy

${ }^{2}$ Istituto di BioFisica, Consiglio Nazionale delle Ricerche, Via La Malfa 153, 90146, Palermo, Italy

${ }^{3}$ Deparmtent of Electronic Engineering, Universitat Politecnica de Valencia, C/ Paranimf 1, 46730, Grao de Gandia, Valencia, Spain

\begin{abstract}
A new prototype of Electronic Nose instrument, Multisensory Odor Olfactory System MOOSY32, with a processing method based on a multivariate classification analysis was used to assess different postharvest and storage treatments effects to Salustiana oranges. The analysis method is based on the measurement of the volatile compounds produced under different environmental and operational conditions. The Electronic Nose system revealed that orange juice flavor changes even when juices are analyzed right after each treatment and fruits are stored under refrigerated conditions. The instrument was able to detect even small changes in the aromatic pattern of the juices, confirming that the packing line itself is able to cause perceptible changes in the flavor. This can be a new and important finding in the Salustiana orange treatment that can lead to a significant improvement of fruits quality on the markets.
\end{abstract}

Keywords: Electronic nose; Orange; Flavor; Ethylene; Coating; Storage; WEKA; ANN

Abbreviations: eNose: Electronic nose; MOOSY32: Multisensory Odor Olfactory System with 32 sensors; MOS: Metal Oxide Semiconductors; VOC: Volatile Organic Compound; WEKA: Waikato Environment for Knowledge Analysis; GNU: Operating system free software; ANN: Artificial Neuron Networks; MLP: Multi-Layer Perceptron; RBF: Radial Basis Function network; IB1: Instance-Based learning; J48: Open source java implementation of the C4.5 algorithm

\section{Introduction}

The electronic nose (eNose) instruments are able to simulate the human nose, replicating the four fundamental functions of the smell sense: detection, recording, memory search and identification. The first two functions are simulated by the use of chemical sensors; the other can be simulated by Artificial Intelligence software [1]. The most common eNoses are based on the use of an array of electronic chemical sensors, with partial or no specificity, coupled with an appropriate system of pattern recognition. The statistical treatments of the data use complex algorithms to extract all the information that can be useful for the different applications [2]. ENose instrument provides a fast comparative measure of patterns of odors, representative of compounds disengaged by a substratum [3], offering a fast nondestructive alternative to sense aroma. In the last decade there have been several reports on electronic sensing in environmental control, medical diagnostics and food industry [4-9].

Regarding citrus several applications of commercial eNose instruments can be found in literature. In most cases the application of these kinds of instruments concerned the authentication, classification and characterization of Citrus spp. [10], or for quality monitoring of mandarins [11] and processed orange juices [12].

The most common sensors used to achieve these objectives are usually Metal Oxide Semiconductors (MOS) sensors. This kind of sensors is based on the interaction with the volatile compounds activates mechanisms of adsorption and desorption, taking place on the surface of sensors and provoking the modification of its electrically measurable properties by a variation of resistance versus time [13]. The general operating principle of a MOS gas sensor is based on the changes that occur in the sensing material when it is heated. In fact when a metal oxide crystal, such as $\mathrm{SnO}_{2}$, is heated, the oxygen is adsorbed on the crystal surface causing a negative charge, and the donor electrons are transferred to the adsorbed oxygen. As a result of this process, a positive charge is formed in a space charge layer forming a surface potential that serve as a potential barrier against electron flow. Inside the sensor, at the level of $\mathrm{SnO}_{2}$ micro crystals, electric current flows and at grain boundaries, the adsorbed oxygen forms a potential barrier that prevents carriers from moving freely. This potential barrier determines the electrical resistance of the sensor. In this way when a deoxidizing gas arrives on the sensor, the surface density of the negatively charged oxygen decreases, so the barrier height in the grain boundary is reduced. The reduced barrier height decreases sensor resistance and increases the electrical conductivity.

The opportunity to apply this kind of technology and instruments directly on line to monitoring the complete process of citrus processing could be of fundamental importance to improve quality of citrus products, ensuring the maintenance of quality throughout all the production chain.

The objectives of this study were: a) to evaluate the quality of 'Salustiana' juice squeezed from fruits previously submitted to postharvest treatments with fungicide, degreening and wax coating, by monitoring the changes in the aroma fingerprint; $b$ ) to evaluate the effect on juices aromatic patterns of different treatments during two different fruits storage conditions; $c$ ) to evaluate the capacity of

*Corresponding author: Pelegri-Sebastia J, Deparmtent of Electronic Engineering, Universitat Politecnica de Valencia, C/Paranimf 1, 46730, Grao de Gandia, Valencia, Spain, Tel: 34 962849404; E-mail: jpelegri@eln.upv.es

Received September 21, 2015; Accepted October 07, 2015; Published October 17, 2015

Citation: Cupane M, Pelegri-Sebastia J, Climent E, Guarrasi V, Sogorb T, et al (2015) Application of MOOSY32 eNose to Assess the Effects of Some Post Harvest Treatments on the Quality of 'Salustiana' Orange Juice. J Biosens Bioelectron 6 : 184. doi:10.4172/2155-6210.1000184

Copyright: (c) 2015 Cupane M, et al. This is an open-access article distributed under the terms of the Creative Commons Attribution License, which permits unrestricted use, distribution, and reproduction in any medium, provided the original author and source are credited. 
prototype designed of eNose, named MOOSY32, to monitoring the change in volatile composition of 'Salustiana' oranges juices obtained from fruits submitted to different postharvest treatments and storage conditions. Moreover, different methods of data classification, such as Bayesian nets, Artificial Neuron Networks and classification tree were applied to analyze the results.

\section{Materials and Methods}

In order to test the ability of the whole eNose system in the detection of the aromatic changes occurring during citrus processing and storage, this investigation was carried out on fruits of 'Salustiana' orange (Citrus sinensis L. Osbeck), purchased from a farm located in Xeraco, in the region of Valencia, Spain. Fruits were harvested at the commercial maturity stage and were passed through to the packing line. Different postharvest treatments were conducted picking up the samples in subsequent step of the packing line, in order to assess the effect of each treatment. Precisely choosen steps were: Control, fruits collected right after harvest; after washing with chemical products (Chemical treatment); after the degreening process with application of ethylene (Ethylene treatment); and after waxing process (Wax treatment). After the treatments, the fruits were transported to the laboratory for applying the different storage tests. Specifically, the samples were analyzed in the first $24-48 \mathrm{~h}$ after harvest (T0). Treated and control fruits were stored at $5 \pm 1{ }^{\circ} \mathrm{C}$ and $85 \% \mathrm{RH}$ for eight weeks and analyzed after four (T1), and after eight weeks (T2) to assess the changes occurring during the storage. After the storage period, a sample of fruits was kept at $20^{\circ} \mathrm{C}$ for 7 days to simulate the shelf-life conditions (T3). Experimental design is showed in Table 1.

For each applied treatment and for each storage time 10 fruits were hand squeezed to extract the juice for the analysis. The aromatic pattern was analyzed with MOOSY32 instrument, using a method based on the measurement of the volatile compounds produced by the fruits under different processing and storage conditions.

The instrument, which is still in the development phase, utilizes 32 commercial MOS sensors of 5 different types, all produced by Figaro Engineering Inc (Table 2). The use of different types of sensors combined with the selected operating temperature leads to a wide range of different responses toward volatile organic compounds with a wide variety of applications (Table 2).

\begin{tabular}{|l|l|}
\hline Treatment & Storage \\
\hline Control & T0 $(0$ week $)$ \\
\hline T1 $\left(4\right.$ weeks at $\left.5^{\circ} \mathrm{C}\right)$ \\
\hline T2 $\left(8\right.$ weeks at $\left.5^{\circ} \mathrm{C}\right)$ \\
\hline Chemical treatment & T0 $\left(8\right.$ weeks at $5^{\circ} \mathrm{C}+1$ week $)$ \\
\hline T1 $\left(4\right.$ weeks at $\left.5^{\circ} \mathrm{C}\right)$ \\
\hline Ethylene degreening $\left.20^{\circ} \mathrm{C}\right)$ \\
\hline \multirow{5}{*}{ treatment } & T3 $\left(8\right.$ weeks at $\left.5^{\circ} \mathrm{C}\right)$ \\
\hline T0 $\left(0\right.$ weeks at $5^{\circ} \mathrm{C}+1$ week at $\left.20^{\circ} \mathrm{C}\right)$ \\
\hline T1 $\left(4\right.$ weeks at $\left.5^{\circ} \mathrm{C}\right)$ \\
\hline T2 $\left(8\right.$ weeks at $\left.5^{\circ} \mathrm{C}\right)$ \\
\hline T3 $\left(8\right.$ weeks at $5^{\circ} \mathrm{C}+1$ week at $\left.20^{\circ} \mathrm{C}\right)$ \\
\hline T0 $(0$ week $)$ \\
\hline T1 $\left(4\right.$ weeks at $\left.5^{\circ} \mathrm{C}\right)$ \\
\hline T2 $\left(8\right.$ weeks at $\left.5^{\circ} \mathrm{C}\right)$ \\
\hline T3 $\left(8\right.$ weeks at $5^{\circ} \mathrm{C}+1$ week at $\left.20^{\circ} \mathrm{C}\right)$ \\
\hline Table $1:$ Experimental design. \\
\hline
\end{tabular}

\begin{tabular}{|l|c|c|}
\hline Model & Target Gas & Typical detection Range \\
\hline TGS2600 & General Air Contaminants & $1-30 \mathrm{ppm}$ \\
\hline TGS2610 - C00 & LP gas & $500-10.000 \mathrm{ppm}$ \\
\hline TGS2610- D00 & LP gas & $500-10.000 \mathrm{ppm}$ \\
\hline TGS2611 & Methane & $500-10.000 \mathrm{ppm}$ \\
\hline TGS2620 & Alcohol, solvents vapor & $500-5.000 \mathrm{ppm}$ \\
\hline
\end{tabular}

Table 2: MOS sensor array configuration of the MOOSY32. Specificity from Figaro.

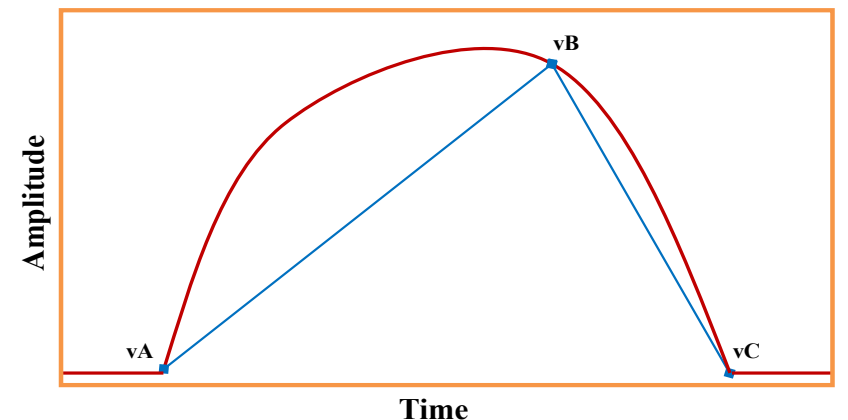

Figure 1: Typical response of sensors to sample air and classification features: $\mathrm{vA}$ ) minimum value of the ascending curve; $\mathrm{vB}$ ) maximum value of the ascending curve; $v C$ ) minimum value of the descending curve.

The whole system composition and operation was already described by Del Cueto Belchi [14]. Briefly, it consists of two parts: the electrical part and the processing of the sample part (prechamber). The prechamber is linked with a clean air pump from which air flow is splitted in two streams, one that goes directly to the sensors and is used as a reference line, while the other passes through the sample chamber to carry the volatile molecules to the sensors chamber. The sensor signal are recorded continuously until the signal of each sensor reaches a steady state, and acquired by a board of National Instruments. Thereafter, the output signals from the sensors are digitized and stored. It is possible to analyze this data in different ways, using different algorithms for the extraction of different features. The classification features utilized for this study were: the minimum (vA) and the maximum $(\mathrm{vB})$ values of the rising part of the curve, the minimum value of the descending part of the curve $(\mathrm{vC})$, and the differences among these values, as dif $\mathrm{A}=\mathrm{vB}$ $\mathrm{vA}$ and $\operatorname{difB}=\mathrm{vB}-\mathrm{vC}$ (Figure 1$)$.

For the analysis, $10 \mathrm{~mL}$ of juice was kept in a Petri dish maintained at $25^{\circ} \mathrm{C}$. Total acquisition time was 3,5 minutes and the air flow was settled at $0.5 \mathrm{~m} / \mathrm{s}$. After 2 minutes of equilibration time, in which the sample was placed in the acquisition chamber, for each analysis 5 measurements were performed with a delay between repetitions of 10 sec.

The e-nose sensors responses were analyzed used a multivariate classification analysis with the software WEKA, using different algorithms. WEKA is an open source software issued under the GNU General Public License [15]. The different algorithms applied were: two probabilistic models, Bayes Net and Naïve Bayes, that calculate a set of probabilities by counting the frequency and combination values on a given data set; two ANN, MLP and RBF, that permit to create a model, during a training test, that is able to classify the data [16]; a classification tree, J48 that is a support system that uses a tree- like graph decisions and their possible after effect; and a lazy algorithm named IB1, that uses the technique of the 'Nearest Neighbour' to classify new instances 
using a similarity function to calculate the similarity between the training instance and the instances of the data set $[17,18]$.

The classification analysis consists in the organization of data in classes, using given class labels to order the objects in the data collection. Classification approaches normally use a training set where all objects are already associated with known class labels. The classification algorithms learn from the training set to build a model. The model is used to classify new objects [19]. ANNs learn from examples through iteration, without requiring a priori knowledge of the relationship among variables under investigation [20].

The results are illustrated in the confusion matrix that represents the accuracy of the solution of the classification problem. It allows the visualization of the performance of an algorithm. Each column of the matrix represents the instances in a predicted class, while each row represents the instances in the actual class. The ideal result is to have all the samples end up on the diagonal cells of the matrix [20]. Figure 2 represent the typical graphical response of the WEKA software for the analysis time $\mathrm{T} 2$, for the analysis parameters $\mathrm{vB}$ and $\mathrm{vC}$.

\section{Results and Discussion}

At the beginning of the data analysis all the responses from the eNose system were used as inputs to the model that was build. The classification was performed separating one subset of samples for training and another for testing, using the cross-validation method. Figure 2 and Table 3 shows the results obtained by the different algorithms to classify fruits from different treatment in each time. It was necessary to use algorithms to test the variables that most strongly influenced the classification. Variable selection consists in the selection of a subset of variables that are the most discriminating [17] (Figure 2).

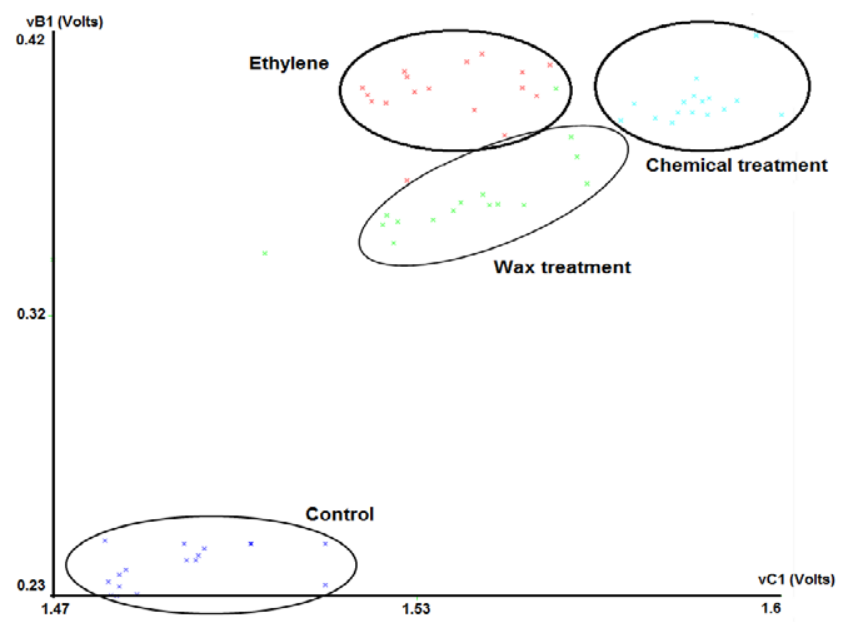

Figure 2: Graphical response of the WEKA software for the analysis time T2. It is possible to observe the analysis parameters $\mathrm{vB}$ and $\mathrm{vC}$.

\begin{tabular}{|c|c|c|c|c|c|c|}
\hline \multirow{2}{*}{$\begin{array}{c}\text { Sample } \\
\text { type }\end{array}$} & \multicolumn{6}{|c|}{ Classifier algorithm \% accuracy } \\
\cline { 2 - 7 } & Bayes Net & $\begin{array}{c}\text { Naive } \\
\text { Bayes }\end{array}$ & MLP & RBF & J48 & IB1 \\
\hline T0 & 92.5 & 95 & 95 & 97.5 & 88.75 & 97.5 \\
\hline T1 & 100 & 100 & 100 & 100 & 96.25 & 100 \\
\hline T2 & 97.5 & 97.5 & 98.75 & 98.75 & 91.25 & 97.5 \\
\hline T3 & 87.5 & 93.75 & 87.5 & 92.5 & 85 & 90 \\
\hline
\end{tabular}

Table 3: Results of the used classification algorithms for the MOOSY32.
For this purpose we used two different algorithms: CfsSubsetEval and GreedyStepWise. The stepwise selection is based on a greedy search that sequentially adds or deletes variables from the pool of total variables [17]. The addiction or deletion of a variable is determined based on the largest improvement in the classification, until the search finds the most influencing variables (Table 3).

The results show high classification accuracy, being able to distinguish among the different juice sample even at $\mathrm{T} 0$, right after each treatment. It is interesting to notice that the applied algorithms proved different performances showing a general decrease of classification accuracy over time and being better in storage time T1, after 4 weeks of storage at $5^{\circ} \mathrm{C}$, and worst in storage time $\mathrm{T} 3$, after the additional storage week at $20^{\circ} \mathrm{C}$. The algorithm $J 48$ permitted the worse classification, and the percentage of accuracy decreased with time.

So, the instrument allowed a good classification of the analyzed juice samples according to the time of storage, and it is possible to highlight a trend in the observed data:

T0: This time gave the worst classification. The aromatic patterns were similar right after the treatments. The lower percentage of classification is caused by confusion between 'Control' and 'Chemical';

T1 and T2: Showed the greater percentage of correctly classified instances with some accuracy difference due to the different instruments and algorithms;

T3: This time permits the worst classification with all the algorithms.

These results are consisting with the hypothesis that initially the aromatic patterns were quite similar (T0), but with slight differences that permitted the classification. Since fruits belonging to the same lot, the differences at T0 can only be due to the applied treatments. Major mistakes in classification were mainly due to un-correct classification of 'Control' and 'Chemical' treated samples.

With advancing of time the aromatic patterns became more different, resulting in an increase of the correctly classified instances. After 4 and 8 weeks of storage (T1 and T2) the instruments were able to better classify the samples, meaning that the major changes occurred during this period. It is possible to suppose that the different treatments caused variations in the internal atmosphere of fruits, probably due to metabolic changes and variations in the respiration rate, as reported in literature [21-23], that led to different VOCs production and consequently to changes in the aromatic pattern.

The last analysis time (T3) gave the worst results. There were no more detectable differences in the aromatic patterns that became similar for all the treatments after a week of storage at $20^{\circ} \mathrm{C}$. All the changes that were stimulated by the applied treatments were amplified by the storage, and overall by the temperature of storage.

\section{Conclusions}

Electronic nose revealed different aromatic pattern of the fruit juices. The MOOSY32 with the processing method used was able to detect variation in the juice aroma even when juices were analyzed right after each treatment (T0). Actually, treatments caused changes in the 'flavor' of orange fruit juices that are easily detected by electronic nose. This confirming that even slight changes in the chemical composition of the volatile fraction can lead to changes in the perceived aroma.

Moreover, the eNose results showed that something changed in the aromatic pattern of orange fruits due to the packing line, and that the pattern of variation is different on the basis of the applied 
storage conditions. Furthermore, there is a major effect due to ethylene degreening and coating, but also control fruits changed their aromatic pattern in response to the storage time and temperature. Storage amplified the effect of each treatment, making possible to distinguish among them.

The eNose results showed that not only coating or degreening caused changes in the aromatic pattern, but also volatile composition is altered as well by passage through the drenching system.

This study suggests that the packing line itself is able to affect the aromatic pattern of oranges, and that this effect is more pronounced when fruits are stored. Particularly, major changes were caused by ethylene and wax applications. Take care in the manipulation of fruits and to minimize the other treatments and the storage times would be an appropriate suggestion in trying to preserve flavor quality of Salustiana orange juice.

\section{References}

1. Win DT (2005) Electonic Nose: a big part of our future. Assumption University Journal of Technology 9: 1-8.

2. Del Cueto Belchi A, Rothpfeffer N, Pelegri-Sebastia J, Chilo J, Garcia Rodriguez D, et al. (2013) Sensor characterization for multisensor odor-discrimination system. Sensors and Actuators A: Physical 191: 68-71.

3. Steine C, Beaucousin F, Siv C, Peiffer G (2001) Potential of semiconductor sensor arrays for the origin authentication of pure Valencia orange juices. $J$ Agric Food Chem 49: 3151-3160.

4. Olarte O, Chilo J, Pelegrí-Sebastia J, Barbé K, Van Moer W (2013) Glucose detection in human sweat using an Electronic Nose. Annual International Conference of the IEEE.

5. Saraoglu HM, Kocan M (2010) Determination of blood glucose level-based breath analysis by a quartz microbalance sensor array. Sensors Journal IEEE 10: 104-109.

6. Horvath G, Chilo J, Lindblad T (2010) Different volatile signals emitted by human ovarian carcinoma and healthy tissue. Future Oncol 6: 1043-1049.

7. Reinhard H, Sager F, Zoller O (2008) Citrus juice classification by SPME-GCMS and electronic nose measurements. Food Science and Technology 41: 1906-1912.

8. Tang KT, Chiu SW, Pan CH, Hsieh HY, Liang YS, et al. (2010) Development of a portable electronic nose system for the detection and classification of fruity odors. Sensors 10: 9179-9193.

9. Lebrun M, Plotto A, Goodner K, Ducamp MN, Baldwin E (2008) Discrimination of mango fruit maturity by volatiles using the electronic nose and gas chromatography. Postharvest Biology and Technology 48: 122-131.

10. Goodner K, Manthey JA (2005) Differentiating orange juice using fourier transform infrared spectroscopy (FT-IR). Proc Fla State Hortic Soc 118: 410 413.

11. Gómez AH, Wang J, Hu G, Pereira AG (2007) Discrimination of storage shelf-life for mandarin by electronic nose technique. LWT - Food Science and Technology 40: 681-689.

12. Shaw PE, Rouseff RL, Goodner KL, Bazemore R, Nordby HE, et al. (2000) Comparison of headspace GC and electronic sensor techniques for classification of processed orange juice. Academic Press LWT 33: 331-334.

13. Aishima T (1991) Aroma discrimination by pattern recognition analysis responses from semiconductor gas sensor. J Agric Food Chem 39: 752-756.

14. Del Cueto Belchi A, Garcia Rodriguez D, Rothpfeffer N, Pelegri Sebastia J, Chilo J (2012) Multi-sensor Olfactory System: using temperature modulation. In: IEEE International Instrumentation and Measurement Technology Conference 1139-1141.

15. Hall M, Frank E, Holmes G, Pfahringer B, Reutemann P, et al. (2009) The WEKA data mining software: an update. ACM SIGKDD Explorations Newsletter 11: $10-18$

16. Batista BL, Silva LRS, Rocha BA, Rodrigues JL, Beretta-Silva AA, et al. (2012) Multi-element determination in Brazilian honey samples by inductively coupled plasma mass spectrometry and estimation of geographic origin with data mining techniques. Food Research International 49: 209-215.

17. Berrueta LA, Alonso-Salces RM, Héberger K (2007) Supervised pattern recognition in food analysis. J Chromatogr A 1158: 196-214.

18. Lajara RJ, Perez-Solano JJ Pelegri-Sebastia IJ (2015) A method for modeling the battery state of charge in wireless sensor networks. Sensors Journal IEEE 15: 1186-1197.

19. Patil TR, Sherekar SS (2013) Performance analysis of Naïve Bayes and J48 classification algorithm for data classification. International Journal of Computer Science and Applications 6: 256-261.

20. Benedetti S, Mannino S, Sabatini G, Marcazzan GL (2004) Electronic nose and neural network use for the classification of honey. Apidologie 35: 1-6.

21. Rodrigo MJ, Zacariás L (2007) Effect of postharvest ethylene treatment on carotenoid accumulation and the expression of carotenoid biosynthetic flavedo orange (Citrus sinensis L. Osbeck) fruit. Postharvest Biology and Technology 43: $14-22$

22. Mayuoni L, Tietel Z, Patil BS, Portat R (2011) Does ethylene degreening affect internal quality of citrus fruit? Postharvest Biology and Technology 62: 50-58.

23. Tietel Z, Porat R, Weiss K, Ulrich D (2011) Identification of aroma-active compounds in fresh and stored 'Mor' mandarins. International Journal of Food Science and Technology 46: 2225-2231. 